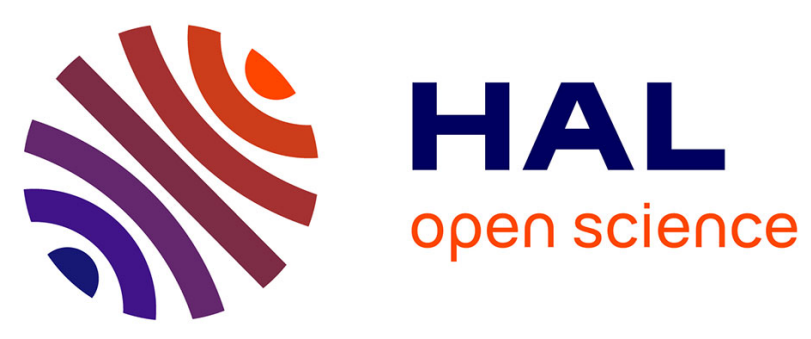

\title{
Hashish Revival in Morocco
}

Pierre-Arnaud Chouvy, Kenza Afsahi

\section{To cite this version:}

Pierre-Arnaud Chouvy, Kenza Afsahi. Hashish Revival in Morocco. International Journal of Drug Policy, 2014, 25 (3), p. 416-423. 10.1016/j.drugpo.2014.01.001 . hal-01048576

\section{HAL Id: hal-01048576 https://hal.science/hal-01048576}

Submitted on 25 Jul 2014

HAL is a multi-disciplinary open access archive for the deposit and dissemination of scientific research documents, whether they are published or not. The documents may come from teaching and research institutions in France or abroad, or from public or private research centers.
L'archive ouverte pluridisciplinaire $\mathbf{H A L}$, est destinée au dépôt et à la diffusion de documents scientifiques de niveau recherche, publiés ou non, émanant des établissements d'enseignement et de recherche français ou étrangers, des laboratoires publics ou privés. 
HASHISH REVIVAL IN MOROCCO (1)

International Journal of Drug Policy

Corresponding author: Pierre-Arnaud Chouvy

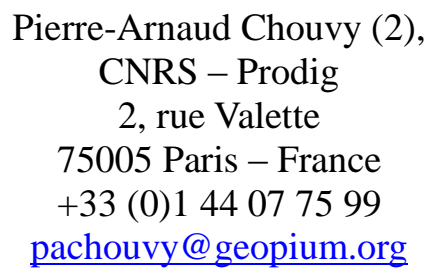

Kenza Afsahi (3)

Clersé

Université de Lille 1 - Bâtiment SH2

59655 Villeneuve d'Ascq Cedex - France

afkenza@yahoo.com 


\title{
HASHISH REVIVAL IN MOROCCO
}

\begin{abstract}
:
Background: In less than a decade, Morocco reportedly saw cannabis cultivation decrease by $65 \%$, and hashish production is widely believed to have followed the same trend. Yet large anomalies exist between the alleged fall of hashish production in Morocco and international seizure data. While no explanation for such a discrepancy existed, the main hypothesis was that cannabis cultivation and hashish production had not declined to the extent suggested by the available information.

Methods: Based on existing data, on interviews with various actors, from European police sources to Moroccan cannabis cultivators, and on field research in Morocco, this article reviews contradictory available data and confronts it with observations made in the field.

Results: In the past decade cannabis cultivation underwent radical changes that could explain the discrepancy between official Moroccan cultivation and production data on the one hand, and international seizures on the other hand. The "traditional" kif cannabis variety is being rapidly replaced by hybrids with much larger resin yields and much higher potency. This unnoticed phenomenon, which slowly started in the early 2000s, explains how a two-third decline in cannabis cultivation was at least partially compensated for by three to fivefold yield increases.

Conclusion: The fact that the massive ongoing switch to hybrid cultivation is largely unknown or unaccounted for is actually a serious issue, for it directly questions the economic strategies that are being implemented in part to reduce and suppress cannabis cultivation in the Rif.
\end{abstract}

Keywords: Morocco, Rif, cannabis, kif, hashish, hybrids, yields. 
In less than a decade, Morocco reportedly saw cannabis cultivation decrease by $65 \%$, from an all-time high of 134,000 hectares in 2003 (UNODC, 2003) to 47,500 hectares in 2011 (UNODC, 2013) (4). Morocco, who was said to be the world's foremost hashish producer in 2003 , is now reportedly second to Afghanistan: Moroccan hashish production allegedly declined by $75 \%$ between 2003 and 2011, from 3,080 tonnes to 760 tonnes (UNODC, 2003; UNODC, 2013). Yet, and regardless of how reliable the Afghan estimates are themselves (5), the recent Moroccan data on hashish production in Morocco has been openly questioned by the European Monitoring Centre for Drugs and Drug Addiction (EMCDDA) and, unofficially, by various European counter-narcotics police services, but not by the United Nations Office on Drugs and Crime (UNODC) (EMCDDA, 2012; UNODC, 2013).

While European and Moroccan seizures of Moroccan hashish have decreased in the past few years, apparently substantiating a decline in resin production in Morocco, the EMCDDA stressed "anomalies" between "the dramatic fall in estimated cannabis resin production in Morocco" and seizure data (EMCDDA, 2012: 58). Indeed, more Moroccan hashish was seized by Morocco, Spain and other European countries, and Algeria, than hashish estimated exported in 2009. In fact, the EMCDDA explained that "adding the quantities seized in Algeria to those intercepted in Spain and Morocco in 2009 would leave no or only very little cannabis resin of Moroccan origin to supply the consumer markets of the 22 European countries mentioning Morocco or Spain as a source of this drug" (EMCDDA, 2012: 58). While the EMCDDA did not offer any explanation for such a discrepancy it did hypothesize that hashish production had not declined to the extent suggested by the available information.

In this article we show that in the past decade cannabis cultivation underwent radical changes that can explain the discrepancy between official Moroccan cultivation and production data on the one hand, and international seizures on the other hand. We confirm the fact that cannabis cultivation has decreased since 2003 and also again since 2005, i.e. since the last UNODC survey, although we were unable to verify the extent of such a decline, as official Moroccan reports or explanations of survey methodology - if proper surveys actually took place - were not made available to us. Yet, we were able to visually confirm in 2013 that cannabis cultivation has disappeared from certain areas where it 
used to be widespread. What is most striking, though, is not the cultivation decrease, but the new cannabis varieties that are now predominantly cultivated in the region. It appears that the "traditional" kif cannabis variety is being rapidly replaced by hybrids with much larger resin yields and much higher potency. This phenomenon, which slowly started in the early 2000 s, can easily explain how a two-third decline in cannabis cultivation was at least partially compensated for by what is a potential three to fivefold yield increase on the vast majority of current cultivated areas. Even if only such a rough guesstimate is possible at this stage, what is clear is that hashish production can no longer be estimated on the basis of former kif-based yields.

This article will first briefly look back at the history and context of kif cultivation and hashish production in Morocco, and especially at how cultivation spread in and beyond the Rif region and how hashish production developed. It will then focus on the last decade or so (2005-2013): puzzling years during which a cultivation decrease was not matched by a decline in hashish production. A decade that also saw important changes in hashish packaging, quality and potency, as shown by police seizures in Europe: smaller hashish pieces of higher quality and higher potency. The last section will detail the new era of hybrid cannabis and highly potent hashish by looking at the various cannabis strains now being cultivated in the Rif and by offering an explanation of when and how the move from the "traditional" kif variety to the new high yield and highly potent hybrids took place. In the end the article will consider the likely future of cannabis cultivation in the Rif, taking into consideration the heavy toll that the new hybrids take on a fragile ecological environment that has already suffered from widespread commercial kif cultivation.

\section{ABOUT THE METHODOLOGY}

To conduct this research, a mixed-methods approach to data collection was employed. First, a review of the (limited) existing literature on cannabis cultivation and hashish production in Morocco was conducted: academic papers, $\mathrm{PhD}$ theses, official reports and statistical data published in French, Spanish and English during the last decades were used to explain how and to what extent cannabis cultivation and hashish production developed and evolved in Morocco. Then, to overcome the limitation of the most recent quantitative data available in the existing literature, and in order to answer the many questions that were left unanswered by this first approach, a qualitative research was 
carried out through interviews and / or unstructured discussions with staff members from international development agencies, European police services, researchers, journalists, activists specialized on cannabis and / or Morocco, and two hashish dealers in France (questions were asked about recent production and trafficking trends, cultivated varieties, cultivation techniques, yields, cultivated surfaces, hashish packaging and qualities, THC contents, seized quantities, production estimates based on seizures, forced eradication, history and current issues of development projects, etc.). The qualitative part of the research was also and most significantly conducted through informal and partially structured interviews with Moroccan cannabis cultivators in the Rif region of Morocco (and with one Moroccan cultivator in Spain) (see below), through the observation and inventory of cultivated cannabis varieties, through the observation of agricultural practices and techniques; and through visual observations of cannabis fields throughout the Rif. It must be stressed here that village names are not divulged in this article and that human sources are anonymized for obvious reasons.

The research process began in 2012 to better understand what had taken place in Morocco since the last UNODC survey (2005), but also to explain why official Moroccan hashish production figures were thought to be underestimated by many observers (notably European police services and the EMCDDA). Crop displacement was quickly set aside as a possible explanation because input by third-party observers and visual observations by the authors dismissed it altogether. Early interviews and a review of the existing literature quickly suggested that cannabis hybrids were being increasingly cultivated in the Rif. To verify this hypothesis a qualitative field study took place in July 2013 in the Rif region where a dozen informal and partially structured interviews were conducted in Arabic with male cultivators in four villages: three located in different areas of the historic cannabis zone, and one outside of the historic zone. Contacts with villagers were initiated as early as 2002 and were increased by chain-referral sampling. Various topics were addressed during these interviews; most notably: new cultivation trends, introduction dates of hybrids, origin of seeds, cultivated varieties, yields, cultivation techniques, hybrid and kif local names, prices (seeds, hashish, well drilling, etc.). Visiting the four villages was done as part of a preplanned driving itinerary meant to allow for as many visual observations as possible (such observations are easily made from the roads as cannabis fields cover entire valleys and hillsides of the Central Rif). Therefore visual observations of cultivated varieties 
(notably using geotagged photographs) were made possible in a large part of the Rif. Information was therefore acquired from primary sources by direct observation and generated empirical evidence. Despite intrinsic limitations (limited surveyed area, limited interviews, no interviews of traffickers, etc.), the mixed methodology allowed the collection and analysis of quantitative and qualitative data and brought convincing answers to the initial research question.

\section{FROM KIF TO HASHISH: A BRIEF HISTORY}

Morocco is a producer of both kif and hashish, although very little kif is produced nowadays and only hashish is exported (Moreno, 1997; Labrousse, Romero, 2001, UNODC, 2003; Chouvy, 2008; Afsahi, 2010). Kif and hashish are derivatives of cannabis (Cannabis sativa or Cannabis indica) (Evans Schultes et al., 1975) whose female plants are the best producers of cannabinoids, the psychoactive compounds that are present in the plant and give marijuana and hashish their potency. Kif, from the Arabic kayf for pleasure (gave kif in French and kef in English, with basically the same meaning as in Arabic), designates a mixture of chopped marijuana and tobacco that was traditionally smoked in Morocco in a small pipe called a sebsi (Afsahi, 2009). But kif is also the Moroccan name for the cannabis plant, a local variety that is adapted to the dryness of the Rif region. Kif is said by many to be a landrace, that is, an old cultivar that was geographically isolated from others and has developed largely by natural processes, by adaptation to the natural and cultural environment in which it grows.

Hashish (from the Arabic for grass) is a psychoactive drug made by compressing the resin glands, or trichomes, of the female cannabis plant. It can be obtained through two different processes, depending on techniques employed in various production areas. In Morocco, the resin glands of the cannabis inflorescence, where delta-9-tetrahydrocannabinol (THC), its main psychoactive substance, is concentrated, are collected by threshing and sieving after the plant has been harvested and dried. Sieving was also the technique favoured in the famous Bekaa valley, in Lebanon, where the renowned Red Lebanon hashish was produced in large quantities up until the early 1990s. Moroccan hashish production techniques (threshing and/or sieving) were most likely imported from Lebanon (Clarke, 1998: 224). The other technique, used only in some parts of Asia, is the hand-rubbing one: much less technical than sieving, it consists of rubbing the flowering cannabis branches back and forth between 
the palms and fingers until the resin builds up on the hands. Such a process occurs only in the Indian subcontinent (Clarke, 1998: 63).

Sieved hashish is much easier and faster to obtain than hand-rubbed hashish since, according to Clarke, one kilogramme $(\mathrm{kg})$ of sieved hashish can be obtained in only a few hours vs. 10 to 25 grams of hand-rubbed hashish by one collector during a full working day. Such a difference not only makes sieving much more suitable for commercial scale production but it also makes sieved hashish more potent since almost all the plant's resin is recovered. Sieving is clearly more efficient than hand rubbing. This does explain in part why 130,000 hectares of cannabis devoted to the production of sieved hashish reportedly (according to the UNODC) made Morocco the world's first hashish producer and exporter in 2003 but also potentially the producer of the world's most potent hashish (UNODC, 2003). Potentially only though, because while sieving can produce a very fine hashish, when completed by heavy threshing, as is the case in Morocco, it "also makes practical the collection of very large quantities of very low-quality powder" (Clarke, 1998), something that the fast-growing Western demand undoubtedly provoked. Obviously, the quality of the end product depends very much on how the threshing and the sieving processes are conducted, based on the producers' goal: large quantities of a lesser quality resin vs. smaller quantities of a high end resin.

In fact, High Times, the largest cannabis-related magazine in the world, reported some twentyfive years ago from the Rif that "the older farmers remember how to make fine hashish but [...] cannot get a high enough price for it to make it worthwhile to produce". As a consequence, "the Moroccans make much more money by selling lesser quality product" (High Times, 1988). Clarke actually goes further when he writes in 1998 that when Moroccan cannabis was cultivated for the production of fine kif, "the plants were very different in appearance from the hashish-producing Moroccan cannabis of today" (Clarke, 1998: 184). A cannabis specialist interviewed by the authors now suggests off the record that Lebanese seeds entered Morocco along with the hashish-making techniques, and that the hashish-making kif plant would in fact have been a hybrid of kif proper and Lebanese varieties. In fact, the early Moroccan hashish reportedly tasted very much like Red Lebanese (communication by a cannabis specialist who interviewed one of the first traffickers of Moroccan hashish, arrested in the mid-1960s). This is most likely what the Moroccan ethnobotanist 
Jamal Bellakhdar refers to when he writes that traffickers introduced new low water varieties in Morocco in the early 1980s: reportedly from the Near East ("cherq"), which was possibly from Lebanon (Bellakhdar, 2008: 230; and personal communication). In any case, in the past, Moroccan cannabis plants were large and well branched; they were spread apart in manured soils and regularly watered. Small plots allowed for slow indoor drying that preserved most of the volatile terpenoids (organic chemicals) and made high-quality hashish production possible. There seemed to be three traditional qualities of the kif plant, ktami, zerwali, and gnawi, all rather water-demanding (Bellakhdar, 1997). Yet, "whatever improvements kif breeders had made in the past have been lost to modern growers. The small, moderately-branched plants growing now, pale in comparison to the bygone traditional plants" (Clarke, 1998: 184). In the end, as Clarke denounces, hashish production became an industry geared towards mass production and "the quality of Moroccan hashish has declined drastically as a result" (Clarke, 1998: 184).

Cannabis was most likely introduced in the Maghreb after the seventh century through the Arab invasions. Yet, very little is known about early cannabis cultivation in the Rif since the region has long been isolated, its Berber inhabitant keeping all foreign visitors at bay until the late nineteenth century. The right to cultivate cannabis in the Rif has first been granted to five douars (villages) by Sultan Moulay Hassan in the nineteenth century. Cultivation was further allowed under the Spanish Protectorate, except for the small period during which Abdelkrim al-Khattabi, the Moroccan Riffian political and military leader, advocated against it. Then, Mohammed V tolerated cannabis cultivation at the onset of Moroccan independence, for tribal discontent with cannabis prohibition had to be quelled in one of the kingdom's poorest regions. People from the region of Ketama now either assert that Mohammed V orally allowed them to cultivate cannabis, or that a 1954 dahir (decree) gives them the official right to do so, even though this dahir clearly does not allow such a thing (Afsahi, 2010). Notwithstanding the illegality of cannabis cultivation in the kingdom, its toleration continued under the reign of Hassan II despite the "war on drugs" he declared in September 1992, which, as the UNODC 2003 Survey showed, fell short of the planned political efforts to step up interdiction, prosecution, and economic development alternatives to wean the Rif from the lucrative drug trade (Chouvy, 2008). 
Cannabis cultivation reportedly stayed under control in a limited geographical area (the socalled historic zone) until the early 1980 s, with probably less than 10,000 hectares cultivated in the late 1970s, up from a few hundred hectares or few thousand only in the early 1970s (Simons, 1995; Anegay, 2001). Cultivation exploded only in the 1980s as a result of complex push and pull economic factors, of which two sets are to be mentioned. First is the economic crisis that unfolded in Morocco and especially in the Rif mountains, where the mechanisation of agriculture was never satisfactorily developed, and where emigration opportunities and the foreign remittances it generated proved insufficient to compensate for the ongoing economic crisis. Second is the growing European demand for hashish that developed during the 1960s and, mostly, during the 1970s and 1980s. This demand is basically what turned the Moroccan cannabis economy from producing the kif mixture to producing hashish (Afsahi, 2009; Afsahi, 2010; Bordes \& Labrousse, 2004; Chouvy, 2008; Clarke, 1998; Labrousse \& Romero, 2001; Moreno, 1997; Mouna, 2010).

Growing European demand and Morocco's closeness to the European booming consumer market most likely spurred hashish production in the Cherifian kingdom, especially in the Central Rif where many say that only the kif plant can be grown. According to Dutch and European Union official estimates cannabis was most likely grown on 25,000 hectares in the mid $1980 \mathrm{~s}$, on 60,000 hectares in 1993, and on 75,000 hectares in 1995 (Clarke, 1998). Then, during the 1980s and the 1990s, cannabis cultivation increased and spread outside of the traditional growing area of the Central Rif as far as the Larache and the Al-Hoceima provinces (Labrousse \& Romero, 2001; Moreno, 1997). The 1980s and 1990s were decades of great change not only for Moroccan hashish production: wars in Afghanistan, Lebanon, and Syria, but also counter-narcotics efforts in Lebanon and Turkey, affected their respective hashish productions, most likely spurring Moroccan production. In the early 2000s cannabis cultivation reached unprecedented surface areas and geographical limits, as shown by the 134,000 hectares grown in 2003 and the 3,080 tonnes of hashish it produced (UNODC, 2003).

\section{TEN PUZZLING YEARS}

According to the last UNODC survey that took place in Morocco, in 2005, only 72,500 hectares of cannabis were grown in the country in 2005 , potentially producing 1,066 tonnes of hashish (UNODC, 2007). Cultivation had reportedly already decreased between 2003 and 2004, down to 
120,500 hectares, but the real decline only occurred in 2005 . The fact that the extent of cannabis cultivation was officially revealed in 2003 by the UNODC most likely played a role in the decline that followed. The Moroccan authorities undoubtedly felt compelled to quickly bring down cultivation. The 2005 decline was attributed in the UNODC report to a drought and to awareness and forced eradication campaigns by the Moroccan authorities (UNODC, 2007). Forced eradication figures were mentioned in the UNODC report, even though the UN agency made clear that it did not verify what was basically unilateral Moroccan data (UNODC, 2007). Out of the 15,160 hectares of cannabis reportedly eradicated in Morocco in 2005, 12,000 were in Larache province, far outside of the Rif proper, and therefore in a region less prone to resistance. 3,000 hectares were also eradicated in Taounate province (out of 12,362 hectares), on the southern limit of the historic cannabis region, but only 150 hectares were targeted in Chefchaouen province (out of 40,529 hectares), basically where part of the historic zone is located, where cannabis cultivation has long been tolerated, and where resistance by the population is potentially more important (UNODC, 2007: 25). The Al-Hoceima province, where a large part of the historic zone lies, was spared by eradication efforts.

While cannabis cultivation did decrease in 2005, it is impossible to assess the eradication effort carried by the Moroccan authorities, if only because the largest eradication measures were taken in the province (Larache) where cultivation was most limited, but also because the Moroccan authorities reportedly eradicated 12,000 hectares in a province where the UNODC survey found only 3,917 hectares of cannabis prior to eradication (UNODC, 2007: 9). A certain level of disagreement between the Moroccan authorities and the UNODC meant that the report on the 2005 survey only came out in 2007 (7), and that it was to be the last such report. As a matter of fact, the UNODC office in Morocco closed in 2006 with no official explanation.

Post-2005 estimates of cannabis cultivation and hashish production in Morocco were subsequently published in the UN World Drug Reports based on official Moroccan data alone: posteradication estimates were of 60,000 hectares in 2009 and in 2010, and of 47,500 hectares in 2010 and in 2011, when 760 tonnes of hashish were reportedly produced (UNODC, 2013). Such data of course raise a few questions about how they were collected. Moroccan official data are most likely produced partly on the basis of the methodology used during the three joint Morocco-UNODC surveys (remote 
sensing combined with sample-based field surveys used to ground-truth satellite images and validate and refine cultivation and production estimates), but it is reasonable to guess that the methodology has evolved, if only because the Moroccan authorities and the UNODC strongly disagreed on the contents of the last UNODC report (see above and note 7). Yet there is a lack of communication by the Moroccan authorities on how surveys are now conducted, or if surveys are even being conducted. While there is no intrinsic reason to doubt Moroccan data, in the end, no data, including that of the UNODC, should be communicated without providing details on how they were collected and processed, or to the very least without offering basic statistical details. As a result, the recent Moroccan data clearly raise more questions than they answer.

First, and as previously mentioned, the EMCDDA pointed to "anomalies" existing between "the dramatic fall in estimated cannabis resin production in Morocco" and seizure data (EMCDDA, 2012: 58). Indeed, more Moroccan hashish was seized by Morocco, Spain and other European countries, and Algeria, than hashish estimated exported in 2009. The discrepancy noted by the EMCDDA is one that is also pointed to by various European counter-narcotics police services who unofficially estimate annual Moroccan hashish production to be somewhere between 2,000 and 3,000 tonnes, that is, far above the official Moroccan estimate of 760 tonnes (2011). Obviously, neither the EMCDDA nor European police services agree with the UNODC when it states in its 2013 World Drug Report that, in Morocco, "the reported decrease in production is substantiated by a decrease in seizures of both resin and kif $[\ldots]$ in the country". The UNODC also explains that the "Moroccan authorities attributed the decline in seizures to increased law enforcement efforts to counter cultivation within the country and to counter trafficking along the country's borders". The UN agency then points to the fact that the "quantities of cannabis resin seized in Spain fell for the third consecutive year", Spain being the country that seizes most hashish in the world (34\% of global seizures in 2011) (UNODC, 2013: 25). In any case, the 2013 World Drug Report did not address the issue raised by the 2012 EMCDDA report and did not question the validity of the Moroccan data.

Second, neither the Moroccan authorities nor the UNODC mention that if seizures did actually decrease, the hashish seized in Europe also changed both in shapes and potency. During the past few years, European counter-narcotics police services noticed that they were no longer seizing the 250- 
gramme soap bars, or savonnettes in French, that made most if not all of their intercepts in the 1980s and 1990s. Most such savonnettes disappeared (except maybe in the United Kingdom, something that is not yet explained) from European seizures and were replaced by 200 -gramme melon-shaped balls, 100-gramme tablets, and 10-gramme olive-shaped pellets (interviews of European police services and discussions with hashish dealers in France).

Third, and most importantly, in the past few years hashish seizures in Europe have shown increasing THC contents. While the traditional savonnettes showed an average THC content of $8 \%$ and were of poor quality, the Moroccan hashish seized in France averaged a $16 \%$ THC content in 2012 according to tests ran by the French Scientific Police. THC contents reportedly reached $10 \%$ in 2007 and $12 \%$ in 2011, with an all-time high of $38 \%$ on at least one 2012 sample (unpublished data provided by the French scientific police, Institut national de police scientifique, or INPS, and the French Monitoring Centre for Drugs and Drug Addiction, Observatoire francais des drogues et des toxicomanies, or OFDT). According to data published by the EMCDDA (Statistical Bulletins available online), hashish potency also increased in Spain, with a $15 \%$ THC content in 2011. It was rather stable in The Netherlands though (16\%), where sample testing is supposed to be the most rigorous in Europe. While it is difficult at this stage to compare THC contents in countries where data are available because very little information exists on how THC testing is carried in different countries (tests are carried on seizures only, with different testing protocols in different countries), it is nevertheless possible to say that hashish THC contents have clearly increased since 2000 in France and Spain, that is, the two largest consumer markets of Moroccan resin. In its 2011 World Drug Report, the UNODC mentioned that the THC contents of hashish in European countries "followed divergent patterns, with some countries showing an increase and others a decrease" but the UN agency did not consider how this could be related to production changes in Morocco (UNODC, 2011: 192).

To sum up, on the one hand, it can be safely assumed that cannabis cultivation has clearly decreased in Morocco, whether to the extent shown by official data or not: while a visual confirmation of an important cultivation decline was made possible by the authors in July 2013 (on the basis of previous observations made by them during the 2000s: many previously cultivated areas were 
cannabis-free in 2013), it is impossible without further methodological details to assess the most recent official Moroccan data. On the other hand, it is also safe to assume that hashish production has not declined to the extent suggested by the most recent official data, something that is clearly suggested by the level of international seizures. While no explanation was provided - whether by the EMCDDA, the UNODC, European counter-narcotics police services, or the Moroccan authorities - to explain for the discrepancy between estimated production levels and existing interception levels, two recent and mostly unnoticed trends gave serious clues to the change in hashish production that is obviously taking place in Morocco.

\section{THE NEW ERA OF HYBRID CANNABIS AND HIGHLY POTENT HASHISH}

In the last few years, and as witnessed in 2013 in the Rif by the authors, the kif landrace (8) has been largely replaced by new cannabis varieties with radically different physical aspects. According to observations made in July 2013 by the authors in dozens of cannabis fields across the Rif, the kif's sativa features gave way to the indica looks of various new varieties in what seems to be the vast majority of cannabis fields (9). While this is only a guesstimate based on visual observations carried across the Rif it is clear that kif cultivation is quickly receding: very little of the kif variety could be seen in the cannabis fields in the summer of 2013. Instead, it seems that out of ten new varieties mentioned to the authors by Moroccan cannabis cultivators, and seen at various occasions by the authors, spread throughout the Rif, one especially, the khardala variety, is now being cultivated across the region. All new varieties appear to be hybrids (10) of various origins and pedigrees, and it can safely be assumed that the ongoing and massive switch to hybrid varieties is the reason why international hashish seizures seem to invalidate the official hashish production estimates in Morocco. Cannabis cultivation has undoubtedly declined to some extent but hashish production levels may well have been maintained. Indeed, according to the cultivators interviewed by the authors during this research, the new hybrids cultivated in Morocco yield three to five times more hashish than the kif variety. And, logically, what is basically a new Moroccan hashish is also more potent, which explains why the THC contents of seized hashish have increased along the past decade.

While some hybrids were spotted in the Rif in the early 2000s during the first UNODC surveys (personal communication by a former UNODC team member), no mention of their cultivation in 
Morocco was ever made by the UN agency in its cannabis surveys or in its subsequent World Drug Reports. Yet a few specimen of a so-called Pakistani variety were noticed and photographed by the above-mentioned UNODC surveyor in 2004, that is, a few years after the first outdoor hybrids were produced in Switzerland's Tessin region, in 1997 (until then, all hybrids, such as the famous skunk variety, were meant to be cultivated indoors). According to a source who was involved in hybrid breeding and cultivation in Switzerland (personal communication by a cannabis specialist), the "Canna Swiss Cups" (Swiss equivalent to the famous Cannabis Cup held in Amsterdam) most likely made the cultivation of hybrids in Morocco in the early 2000s possible. It is therefore possible that the aforementioned "Pakistani" variety may well have been a hybrid of various sativas adapted in Switzerland, where cannabis cultivation was considered legal during seven years, and of Afghan inbred lines (well known varieties such as Afghani\#1 or Kush\#1). The first hybrid seeds to be sown in Morocco may also have been imported from The Netherlands, where cannabis hybridization has a long history, or from Belgium and The Netherlands by Moroccan bar and coffee shop owners in the late 1990s. Also, hybrid seeds are now clearly being introduced in Morocco from Spain, where cannabis seed breeders are competing with Dutch seed breeders (interview in Spain and in Morocco with Moroccan cannabis cultivators who import seeds from Spain). Yet at this stage very little is known about the nature of the varieties now cultivated in Morocco, or about how and by whom the seeds have been introduced in the country: only hypotheses can be proposed at this point. What is known is that the new varieties are hybrids of indicas and sativas with high resin yields and high THC contents. It is highly likely that the seeds are mostly introduced by foreigners (whether involved only in trafficking, or also directly involved in cannabis growing and hashish production), by Moroccan traffickers (beznassa), and, most likely to a lesser extent, by Moroccan growers themselves (those who can travel to and from Spain or The Netherlands for example) (Bellakhdar, 2003). What is agreed upon by the cultivators interviewed during this research is that hybrid cultivation is most often undertaken to meet a growing outside demand: hybrid cultivation seems to be to a large degree a demand-driven phenomenon.

The existence of cannabis hybrids in Morocco is still a largely unnoticed phenomenon. This is despite the fact that the presence of hybrids in Morocco has been debated about and commented for 
years on various cannabis-related forums on the Internet, with regular mentions of Pakistani, Mexican, and Jamaican hybrids: a simple search on such forums yields many detailed descriptions of the new hybrids and even some cultivation details. Also, a few 2006 photos (according to Exif metadata) of what is most likely the Pakistani variety could also be found pinned on Google Earth in the heart of the Rif. Later on, a 2010 movie documentary (11) by the Strain Hunters (12), a filial of the Green House Seed Company, one of The Netherlands' most famous seed breeders and regular winner of the annual High Times Cannabis Cup (Amsterdam), focused on the fast increasing cultivation of the Pakistani variety in the Rif. While the Strain Hunters' movie is full of historical and cultural approximations and mistakes on Morocco and the Rif, it is nevertheless a worthwhile documentary made by expert cannabis breeders, who were amongst the first to witness the spread of hybrids in Morocco.

The fact that cannabis cultivation is diversifying and that kif cultivation is diminishing across most of the Rif was made obvious by the collection in July 2013 by the authors of this research of new names given to the kif plant. The kif is now very often called beldiya (from the Arabic bled: country, countryside, local), maghribiya (Moroccan), aadiya (regular), or kdima dyalna (our old one) (interviews with cannabis cultivators). Previously, the most frequent names given to the kif were naanaa (mint) and aachba (stem, stalk) (Afsahi, 2009). Some of the hybrids that are now cultivated in the Rif have names that stress their foreign origins: this is the case of the gaouriya (European in Moroccan slang) and the romiya (from Romans, the foreigner). The so-called Pakistani variety is called pakistana, and there is also mention of the jamaicana, the mexicana, the marijuana, the avocat (avocado), and the hajala (the widow: a feminized variety). Interestingly, the name khardala, that of the most widespread variety in the Rif in 2013, means mix or blend. Yet the khardala is also called berraniya (the stranger). While it has definite sativa features that makes it look very much like kif (the kif is a sativa variety), its indica characteristics are mentioned by the cultivators: it is said to be full and plump (maamra ou ghlida) and some, but not all, dislike the taste, the smell and even the effect of its resin (tatkherdel: that drives one crazy). It seems that the pakistana, an indica dominant variety, is no longer cultivated in the Rif (none could be found by the authors in 2013) and that it was replaced by the khardala, a sativa dominant variety. Some cultivators seem to think that the gaouriya, 
a wide and low indica dominant variety with higher yields and higher THC content, is likely to replace the khardala in the coming years (interviews with cannabis cultivators).

According to various accounts by local growers, the Pakistani variety was not adapted to the Rif, and did not offer high enough resin yields (although yields are not clear). The khardala, a hybrid of unknown pedigree, resembles the kif very much but grows significantly wider with definite indica features and qualities (most notably broad leaves and a higher potency). One such feature, of course, is its long growth period: it is sown in April or May and cut in October, that is, much later than the kif (sown in February or March and cut in July or August). The late drying period is actually a problem for the crops cannot be dried on rooftops (13) after summer has ended and because indoor drying spaces are far from being always available. Of course this is something that can affect the quality of the end product. One hundred $\mathrm{kg}$ of cut khardala can reportedly yield up to $7 \mathrm{~kg}$ of resin the first year, $5 \mathrm{~kg}$ the second year, and $3 \mathrm{~kg}$ the third year, when new seeds need to be purchased. This amounts to potentially high extraction rates: $7 \%$ the first year and, if the seeds produced the first year are sowed, $5 \%$ the second year and 3\% the third year with an average extraction rate of $5 \%$ over three years, which is basically the extraction rate mentioned by most cultivators (interviews with cannabis cultivators). This is much higher than what the kif variety could produce in the early 2000s according to the UNODC surveys: $2.8 \%$ in 2004 and a mere $2 \%$ in 2005 (UNODC, 2007). In Hashish! Robert Clarke mentions that in 1987 a team of four experienced people working about 10 hours could extract between $2.25 \%$ and $4.25 \%$ of resin (depending on quality) out of $200 \mathrm{~kg}$ of kif (Clarke, 1998: 222). While the resin yields of the gaouriya are not known (only small test plots could be observed by the authors), they are said to be higher than those of the khardala (interviews with cannabis cultivators).

Lower needs in water also make the gaouriya more attractive, since water extraction and irrigation techniques are expensive. This is actually one of the most important changes in cannabis cultivation practices in the Rif: while kif was predominantly cultivated on bour (rain fed), the new varieties must absolutely be grown on irrigated land (interviews with cannabis cultivators and observations by the authors). The kif produced less resin but was adapted to the Rif's dryness and could sustain high levels of water stress. Only $12 \%$ of cannabis fields were irrigated in 2004, $20 \%$ in 2005 (UNODC, 2007). The new hybrid varieties require a lot of water. In a dry country with very 
little rain, where the lack of springs prevents the traditional flood irrigation in most places, only water tanks and wells make irrigation possible. Countless water tanks dot the cannabis-covered valleys and slopes, and wells are now reportedly dug on a much frequent basis and at much deeper depths. The typical large 15-meter deep hand-dug wells just cannot deliver enough water to irrigate what has mostly become hybrid cultivation. As a result, drilling companies have made much deeper and narrower machine-drilled wells much more common in the Rif and 100-meter deep wells are now common. As a consequence irrigation costs have largely increased of course, not only because well drilling is expensive but also because motor pumps, irrigation hoses and sprinklers are needed. In fact, the hybrid rush has become a water rush as even the deep wells empty quickly and as new wells are frequently needed (interviews with cannabis cultivators).

Scarce water resources end up being wasted by poor and sometimes detrimental irrigation techniques (observations by the authors). Most cannabis fields are equipped with sprinklers that are too often used at midday, when evaporation is at its highest. This is because many cannabis growers do not own enough sprinklers and have to move them from place to place across their fields from dawn to dusk (observations by the authors). Beyond wasting water, sprinklers also inevitably affect the trichomes and the volatile terpenoids and, by consequence, resin production. Cannabis cultivation techniques are still very basic in the Rif, for no or very little drip or wick irrigation is used (more efficient use of water), because broadcast seeding is still widespread, and because precise seeding - or even better, greenhouse germination - is too rare (resulting in denser crops, but also shorter and stunted unbranched plants) (14). Also, chemical fertilizers are used more often than manure and while they make cannabis plants mature faster, often before resin maturity, they also tend to affect the smell and taste of the end product (Clarke, 1998: 191; and observations by the authors). Khardala cultivation also largely occurs by sowing seeds that were obtained during the previous harvest on seeded plants, something that proves detrimental to hashish yields, and that is clearly inadvisable (interviews with cannabis cultivators). Indeed, since the khardala variety is a hybrid, it is not a trueto-type variety that can be safely reproduced from its own seeds (contrary, to some extent, to the kif landrace / heirloom). Also, since it is not a feminized variety, female plants often get pollinated either by the rare male plants that inevitably escape manual pulling, or through the hermaphroditism 
phenomenon: cannabis is a monoicous plant and separate male and female flowers can be present on the same individual, with self fertilization as possible result. In the end it appears that if the new varieties offer much higher yields than the kif plant, and especially the recent and impoverished kif variety, the Rif's full hashish production potential has not yet been reached. Newer varieties and better cultivation techniques can undoubtedly yield higher hashish production. Still, the cultivation of the khardala variety easily allows for threefold increases compared to what kif cultivation can produce. In the end, a two-third decline in cannabis cultivation since 2003 is very likely to have been offset by the yield increase allowed by the cultivation of the new hybrids on the vast majority of the actual cannabis surface.

\section{A doomed revival?}

Moroccan cannabis cultivation started declining when new hybrid varieties were introduced in the country. Yet correlation is not causality, and it does not seem that the cultivation decline is what caused the resort to hybrids. It is not clear what role forced eradication might have played, since it mostly took place outside of the historic cannabis zone of the Central Rif. In any case, forced eradication was stopped in 2011 (USDS, 2012) partly in reaction to the Arab Spring (15) and to the 2010 Bab Berred demonstrations. In the end, other factors are more likely to have caused the actual hashish revival in the country. The Moroccan kif-based hashish industry suffered from producing large quantities of low quality hashish of bad reputation among European consumers. This low potency hashish that was almost systematically cut with adulterants ended up suffering from commercial European indoor cannabis cultivation (notably in Vietnamese-ran greenhouses in France or the United Kingdom, especially since the early 2000s). European hashish aficionados could even produce their own high quality hashish by resorting to expert extraction techniques: water-based or gas-based extraction devices (already used in Afghanistan in the 1970s) as well as Pollinators (16) are sold in Europe and are allegedly now also used in Morocco to produce high-end hashish that could supposedly not be produced by threshing and sieving. While these extraction techniques could not be observed in Morocco by the authors, there are nevertheless accounts by individuals of Pollinators bought by Moroccan producers in Northern Europe and shipped to Morocco (personal communications by direct witnesses). What is clear is that the Moroccan hashish industry is being 
modernized with large-scale cultivation of hybrid varieties imported from Europe, most likely both by Moroccan and European growers and traffickers. Moroccan hashish is now much more potent than it used to be, and it is now sold in Europe in new shapes and sizes. It seems, though, that most of the seized hashish is still mixed in the same proportions than before and with the same adulterants (unpublished data provided by French Scientific Police: INPS).

Such a hashish revival, though, is still unaccounted for by most international and national agencies dealing with drug issues or the economic development of the Rif region. The 2012 International Narcotics Control Strategy Report (INCSR) of the United States Department of State (USDS), for example, considered that "Morocco has made significant efforts to combat the production and trafficking of narcotics". It also estimated that Morocco had employed "a multi-faceted strategy that couples law enforcement, crop eradication/replacement, and demand reduction/treatment efforts with economic development measures to erode the cannabis growing culture" (USDS, 2012). Yet no mention of hybrid cultivation, of higher hashish yields, or of higher THC contents, was made in the report, even though it acknowledges that while "the GOM has had success encouraging the cultivation of alternative crops, some farmers have resisted this policy".

The fact that the massive ongoing switch to hybrid cultivation is largely unknown and unaccounted for is a serious issue, for it directly questions the economic strategies that are being implemented against cannabis cultivation in the Rif. Ignoring or misunderstanding the drivers of the hashish economy as well as its net returns (potentially increased through hybrid cultivation), does not bode well for the success of the important development programmes that are underway in the region. Millions of Euros are being spent in the Rif on integrated development programmes (17) that are highly unlikely to have been designed to address the issues raised by the widespread cultivation of hybrids. Also, looking back at the history of economic development in the Rif does not augur well for the economic development of the region's cannabis growing areas when the failure of completed programmes is acknowledged. Indeed, postcolonial rural development projects in the Rif started in 1961 with the DERRO (UN / FAO) project and have failed to achieve economic development in the Rif. Similarly, the very few alternative development projects that took place in the Rif have failed to diminish or even contain cannabis cultivation in the region (Afsahi, 2009; Chouvy, 2008) and some 
reportedly even had counterproductive unintended consequences (Boujrouf, 1996). One such project, for example (PMH Nord project led by the AFD between 1997 and 2002, at a cost of 4 million Euros), aimed at reducing cannabis cultivation in an area by extending an irrigation perimeter and by modernizing irrigation techniques. Although such a phenomenon had already happened with opium poppy cultivation in southern Afghanistan and in other countries (Chouvy, 2009), the project eventually led to an increase of cannabis cultivation after the farmers chose to irrigate cannabis fields rather than alternative crops (interview with a development worker involved in the project). Coupled with a misunderstanding or ignorance of what is basically a new cannabis economy, a limited knowledge of past failures, and the related limitations of alternative development programmes, is of course a real concern for the region.

To make things worse, the Rif is an environmentally fragile region that is one of the poorest and most densely populated in Morocco. The fast increase of cannabis cultivation during the last decades along with poor soil conservation practices has taken a heavy toll on the Rif's forests and fragile ecosystems (Afsahi, 2009; Chouvy, 2008; Grovel, 1996). While cannabis cultivation has declined in the past ten years, the switch from the mostly rainfed kif plant to the systematically irrigated new hybrid varieties puts the region's limited water resources at risk. In the same way as the old kif landrace is said to have disappeared with the development of the hashish industry, the modern kif, so to speak, could also disappear, replaced with hybrids that can potentially fast deplete water resources. The ongoing hashish revival might well be short-lived after all. Ironically, a legalization debate is gaining momentum in Morocco, reaching even the parliament (2013), where the use of kif for medicinal purposes is being discussed. While many cultivators say that nothing but kif can grow in the Rif, or at least that the kif economy is the only one viable in the Rif (even more so considering the most recent free trade agreements between Morocco and the EU), such a debate proves timely.

In the end, while it can be safely assumed that cannabis cultivation has clearly decreased in Morocco, whether to the extent shown by official data or not, it is safe to estimate that hashish production has not declined to the extent suggested by the most recent official data, something that is clearly suggested by the level of international seizures. While no explanation was provided - whether by the EMCDDA, the UNODC, European counter-narcotics police services, or the Moroccan 
authorities - to explain for the discrepancy between estimated production levels and existing interception levels, two recent and mostly unnoticed trends gave serious clues to the change in hashish production that is obviously taking place in Morocco. Clues that production changes are taking place in Morocco include the modification in the shapes and potency of the hashish seized in Europe, and the increasing THC content of hashish seizures in Europe.

Field observations and interviews show that kif cultivation is quickly receding: indeed, very little of the kif variety could be seen in the Rif's cannabis fields in the summer of 2013. The old Moroccan landrace is being quickly replaced by about ten new hybrid varieties, including the widespread khardala. It can safely be assumed that the ongoing and massive switch to hybrid varieties is the reason why international hashish seizures seem to invalidate the official hashish production estimates in Morocco. Cannabis cultivation has undoubtedly declined but has been modernized, allowing for considerably higher hashish yields that explain why and how hashish production levels may have been maintained. Also, what is basically a new Moroccan hashish is also more potent, which explains why the THC contents of seized hashish have increased along the past decade. Yet such a hashish revival is still unaccounted for by most international and national agencies dealing with drug issues or the economic development of the Rif region. This obviously does not bode well for the ecological and the economic future of the Rif and the Riffians who have already seen too many development programmes fail them.

\section{Endnotes}

1) This article is part of the LINKSCH Research Project, funded by the European Commission. The authors wish to acknowledge the help of Laurent Appel, Laurent Laniel, Alex Marshall, Pascual Moreno, Khalid Mouna, Lluis Romero as well as a few others who cannot or do not want to be mentioned here.

2) Pierre-Arnaud Chouvy holds a $\mathrm{PhD}$ in geography from the Sorbonne University and is a geographer and research fellow at CNRS-Prodig, Paris, France. He is the author of Les 
territoires de l'opium (2002, Genève: Olizane), Yaa Baa (2004, Singapore: Singapore University Press), and Opium. Uncovering the Politics of the Poppy (2009 / 2010, London / Cambridge: I.B. Tauris / Harvard University Press).

3) Kenza Afsahi holds a PhD in economy from Lille 1 University (France), is a member of the Clersé (Lille Centre of Sociological and Economic Research) research team, and currently works on cannabis production and consumption.

4) Cultivation estimates are given after eradication (8,000 hectares in 2011). The 2003 and 2005 estimates are based on joint surveys by Morocco and the UNODC while the 2012 estimate is based on data gathered unilaterally by the Moroccan authorities, then communicated to the UNODC. While the methodology used in the 2003 and 2005 surveys are detailed in the UNODC reports (use of both remote sensing and field sample-based field surveys), no information is available as how the 2012 data were produced.

5) For example, prior to the 2012 survey, estimates of the Afghan cannabis survey used a visual estimate for the upper figure and a satellite estimate for the lower estimate in the range.

6) In all hybrid crosses, the female seed parent is listed before the " $\mathrm{x}$ " and the male pollen parent is listed after the "x". If the sexual identity of the parents is unknown, a "/" symbol is used rather than the " $\mathrm{x}$ ".

7) The UNODC explained in a 2006 preliminary version of the 2007 report that validation by the Moroccan authorities was taking more time than expected. It is likely, though, that the discrepancy between the Larache cultivation estimates and the alleged eradicated surface delayed a publication in which the discrepancy was neither solved nor acknowledged.

8) A landrace, or heirloom, is an old cultivar that was geographically isolated from others, resulting in inbreeding and indigenousness: it has developed largely by natural processes, by adaptation to the natural and cultural environment in which it lives. A landrace is also called a heirloom variety, that is, a variety that is old (before 1951, when the first vegetable hybrids were introduced) and, is open-pollinated. Landraces are usually more 
genetically and physically diverse than formal breeds. While many seed breeders refer to the kif variety as a landrace or heirloom, it can be safely assume that it became an inbred line (IBL) long ago: a variety that has been selectively inbred to stabilize certain traits in the variety, with great uniformity of plants and no phenotype variation (quick flowering, large amount of resin, but variations in height and leaf shapes between seedlings for example). Afghani\#1, for example, is an IBL selectively bred from several different Afghani landraces. 9) Sativa cannabis plants grow fast, are tall and thin, with light green narrow leaves. After flowering, sativa plants can reach maturity within 10 to 16 weeks. They are originally from Colombia, Mexico, or Thailand. Indica cannabis plants are short, wide and dense, with dark green broad leaves. Having more chlorophyll than sativas (who require more light) they mature in 6 to 8 weeks and have higher yields. Indicas mostly originate in Afghanistan and Pakistan. According to a new taxonomic treatment of cannabis devised by botanists Robert Clarke and Mark Merlin (Clarke \& Merlin, 2013), a distinction is made between narrow-leaf hemp (NLH) and broad-leaf hemp (BLH), along other distinctions based on different cannabis gene pools: it is meant to "resolve previous taxonomic discrepancies" (ibid. p. 9).

10) A hybrid (or genetics in the cannabis seed breeder and pot growing community) is the result of crossing two separate IBLs by controlled pollination, sometimes by hand-pollination. Hybrids are usually more vigorous (faster growth and higher yields) than either of their parent IBLs but they are likely to show a greater degree of variation between seedlings but with only minimal phenotype variation between seedlings. Yet, while hybrids have many qualities, to the difference of heirloom varieties they have a lower ability to reproduce themselves "true to type". An F2 (Fililal 2) hybrid is the result of self or cross pollination of an F1, without the consistency of the F1 hybrid.

11) http://www.strainhunters.com/ (page visited on the first of October 2013).

12) Strain is a term that is mentioned very often in texts and talks about cannabis even though it lacks an official ranking status in botany. A strain is a designated group of offspring that are descended from a modified plant, whether it was produced by conventional breeding or by genetic mutation. 
13) Another "traditional" technique that proves detrimental to hashish quality because the wind blows away the very volatile terpenoids. Clarke explains that while plants dry faster in the sun than indoor (5 to 7 days vs. 10 to 14 days) the sun bakes out the terpenoids and makes the resin less moist and sticky. Also, light and heat tend to alter THC and lower the final potency (Clarke, 1998: 188).

14) The kif also increasingly suffers from flat stems or fasciation: a flat unbranched stem topped with only one flat flower. Fasciation obviously affects resin yields.

15) According to the United States Department of State, the Moroccan government cited "several reasons for this policy, including the effectiveness of ongoing surveillance of illicit crops" (USDS, 2012).

16) Pollinators were invented in 1993 in The Netherlands by Mila Jansen and are a fast and very effective way of extracting resin without any leaf material, dirt or other impurities. The Pollinator was the first machine ever designed to produce hashish. It was followed in 1998 by the Ice-O-Lator in which an even purer resin is extracted with both water and ice.

17) The Moroccan Agency for the Promotion and Development of the North (APDN) launched a one billion Dirham programme (120,000 U.S. Dollars or 89,000 Euros) as part of the Moroccan government's "voluntarist policy to fight cannabis cultivation" in the provinces of Al Hoceima, Chefchaouen, Larache, Taounate and Tetouan. After this first Global Integrated Rural Development Program (GIDP), the APDN and its partners planned to mobilize about 3.4 billion Dirhams in the context of a Global IDP (2010-2013) towards more than 200 rural districts and not only towards the initial 74 or 75 rural communities (see www.apdn.ma). While such a large-scale development programme does focus to some extent on the cannabis economy in the Rif it is not clear if the dramatic changes that occurred during the last decade were integrated in the programme's design. In any case, it seems very unlikely that the important economic changes generated by the switch from kif to hybrids was considered in the context of the Second Pillar of the Plan Maroc Vert (2008-2020), or Green Morocco Plan, a development scheme aimed at improving agriculture launched by Morocco in 2008. The Second Pillar specifically targets the upgrading of the most vulnerable areas and 
populations of the kingdom. The Rif is of course included in this 68 million Euro programme funded at $74 \%$ by the AFD (AFD, 2012). The project, which started in 2012 and is coordinated by the new Moroccan Agence pour le développement agricole (ADA, or Agency for Agricultural Development, created in 2009), also aims, to some extent, at curbing cannabis cultivation in the Rif.

\section{Bibliography}

Afsahi, K. (2009). Les producteurs de cannabis dans le Rif-Maroc: Étude d'une activité économique à risque, Thèse de doctorat en économie. Lille: University of Lille 1.

Afsahi, K. (2010). Cannabis cultivation practices in the Moroccan Rif. In T. Decorte et al., 2010, World Wide Weed. Global Trends in Cannabis Cultivation and its Control, Farnham: Ashgate, pp. 90-114.

AFD (Agence française de développement). (2012). Accompagner la mise en place du Plan Maroc Vert. March 2012, Paris : AFD.

Anegay, K. (2001). Introduction et développement des cultures alternatives dans le Rif marocain (phase II). Rabat : APDN.

Bellakhdar, J. (1997). La pharmacopée marocaine traditionnelle. Paris: Ibis Press.

Bellakhdar, J. (2003). Le Maghreb à travers ses plantes. Casablanca : Editions le Fennec.

Bellakhdar, J. (2008). Hommes et plantes au Maghreb. Eléments pour une méthode en ethnobotanique. Metz : Plurimondes.

Bordes, P., Labrousse, A. (2004). Économie de la drogue et réseaux de corruption au Maroc. Politique Africaine. $\mathrm{N}^{\circ}$ 93, pp. 63-82.

Boujrouf, S. (1996). La montagne dans la politique d'aménagement du territoire au Maroc. Revue de géographie alpine, 1996, n 4, pp. 37-50. 
Chouvy, P.-A. (2008). Production de cannabis et de haschich au Maroc: contexte et enjeux. L'espace politique, $\mathrm{n}^{\circ} 4$, pp. 5-19.

Chouvy, P.-A. (2009). Opium. Uncovering the Politics of the Poppy. London: I.B. Tauris.

Clarke, R.C. (1998). Hashish! Los Angeles: Red Eye Press.

Clarke, R.C., Merlin M. D. (2013). Cannabis. Evolution and ethnobotany. Berkely: University of California Press.

EMCDDA (European Monitoring Centre for Drugs and Drug Addiction). (2012). Cannabis production and markets in Europe. EMCDDA Insights. Luxembourg: Office for Official Publications of the European Communities. See also Statistical Bulletins at www.emcdda.europa.eu.

Grovel R. (1996). La préservation des forêts du Rif centro-occidental: un enjeu de développement de la montagne rifaine. Revue de géographie alpine, $\mathrm{n}^{\circ}$ 4, pp. 75-94.

High Times (Unknown author). (1988). The Modern Moroccan. High Times. July 1988.

Labrousse, A., Romero, L. (2001). Rapport sur la situation du cannabis dans le Rif marocain, Paris : Observatoire français des drogues et toxicomanies (OFDT).

Labrousse, A. Romero, L. (2002). Maroc: la production de cannabis dans le Rif, Drogues Trafic International, Observatoire français des drogues et toxicomanies (OFDT), $\mathrm{N}^{\circ}$ 13, février 2002

Moreno, P. (1997). Estudio del cultivo de cannabis sativa en el Rif marroqui : sus consecuencias socioéconomicas para la región, Universidad politécnica de Valencia, Ecuela Téchnica Superior de Ingenieros Agronomos, Dpto. De Economía y Ciencias Sociales, December 1997.

Mouna, K. (2010). Le bled du kif. Economie et pouvoir chez les Ketama du Rif. Paris : Ibis Press. 
OGD (Observatoire géopolitique des drogues). (1994). Rapport d'enquête sur les enjeux politiques, économiques et sociaux de la production et du trafic des drogues au Maroc, Unité drogues, Secrétariat général de la Commission des Communautés européennes.

Simons, M. (1995). Signs in Wind of Morocco Drug Crop. The New York Times. June 18, 1995, p. 15.

USDS (United States Department of State). (2012). International Narcotics Control Strategy Report 2012. Bureau for International Narcotics and Law Enforcement Affairs, Washington D.C.: Department of State.

UNODC (United Nations Office on Drugs and Crime). (2003). Maroc. Enquête sur le cannabis 2003, Vienne: United Nations.

UNODC. (2006). «Review of the world cannabis situation », Bulletin on Narcotics, Volume LVIII, Nos. 1 and 2.

UNODC. (2007). Maroc. Enquête sur le cannabis 2005 - Rapport préliminaire, Vienne: United Nations.

UNODC. (2011). World Drug Report 2011. Vienna: UNODC.

UNODC. (2013). World Drug Report 2013. Vienna: UNODC. 